\title{
Induced Resistance as a Possible Means to Control Diseases of Strawberry Caused by Phytophthora spp.
}

\author{
H. Eikemo, A. Stensvand, and A. M. Tronsmo, The Norwegian Crop Research Institute, Plant Protection Center, \\ Høgskoleveien 7, N-1432 Ås, Norway
}

\begin{abstract}
Eikemo, H., Stensvand, A., and Tronsmo, A. M. 2003. Induced resistance as a possible means to control diseases of strawberry caused by Phytophthora spp. Plant Dis. 87:345-350.

Two putative elicitors of disease resistance (acibenzolar- $S$-methyl and chitosan) were tested for their effect on crown rot (Phytophthora cactorum) in strawberry. The effect of both compounds was enhanced when the time between treatment and inoculation was prolonged from 2 to 20 days. There were no significant differences between treatments when the concentration of acibenzolar- $S$-methyl was increased from 10 to $1,000 \mu \mathrm{g}$ a.i./plant. The lowest tested concentrations of chitosan (10 and $50 \mu \mathrm{g}$ a.i./plant) resulted in a lower disease score compared with the highest concentrations ( 250 or $1,000 \mu \mathrm{g}$ a.i./plant). There were no differences in disease score between treatment with fosetyl-Al, acibenzolar-S-methyl, or chitosan when applied 5 or 15 days before inoculation. The effect of acibenzolar- $S$-methyl and chitosan also was tested against $P$. fragariae var. fragariae in alpine strawberry (Fragaria vesca var. alpina cv. Alexandria). Chitosan had no effect, whereas fosetyl-Al and all treatments with acibenzolar- $S$-methyl (50 or 250 $\mu \mathrm{g}$ a.i./plant; $5,10,20$, or 40 days before inoculation) reduced the severity of the disease. There were no significant differences between acibenzolar- $S$-methyl and fosetyl-Al when applied at the same time. Acibenzolar- $S$-methyl and chitosan at concentrations of $0.5,5,50$, and $500 \mu \mathrm{g}$ a.i. $\mathrm{ml}^{-1}$ in V8 juice agar were tested for possible effects on $P$. cactorum and $P$. fragariae var. fragariae in vitro. Only chitosan at concentrations of 50 and $500 \mu \mathrm{g}$ a.i. $\mathrm{ml}^{-1}$ had a growthretarding effect on $P$. cactorum. Both acibenzolar- $S$-methyl and chitosan at a concentration of $500 \mu \mathrm{g}$ a.i. $\mathrm{ml}^{-1}$ reduced the growth rate of $P$. fragariae var. fragariae.
\end{abstract}

Additional keywords: Aliette, Bion, defense activators, red core, red stele

Phytophthora cactorum (Lebert \& Cohn) J. Schröt. has been known as the cause of crown rot in strawberry (Fragaria $\times$ ananassa Duchesne) since it was first reported on cv. Ydun from Germany in 1952 (7). Since then, it has been detected in many countries in Europe and other parts of the world. Since its first report in Norway in 1992 (27), it has been found in more than 100 locations throughout the country. Red stele, caused by $P$. fragariae C. J. Hickman var. fragariae, has been detected in many countries since it was first reported from Scotland in 1927 (30). It was first discovered in Norway in 1995, but thus far has been detected only in a limited number of fields (26). Both organisms are difficult to eradicate from soil because they produce resting spores (oospores) that can survive for many years, and there are few means of eliminating them once a field has become infested. Aliette $80 \mathrm{WG}$ (fosetyl-Al) is the only fungicide allowed on strawberry in Nor-

Corresponding author: H. Eikemo

E-mail: haavard.eikemo@planteforsk.no

Accepted for publication 4 October 2002.

Publication no. D-2003-0123-01R

(C) 2003 The American Phytopathological Society way that has a satisfactory effect against crown rot and red stele. Fosetyl-Al, combined with the use of disease-free planting material and improved soil drainage, is the most important means of disease management $(9,18,24)$. An additional possible control measure is the use of resistant cultivars; however, the most commonly grown cultivars in Norway are susceptible to both these diseases $(9,26)$. Another approach might be to exploit induced resistance. Localized treatment of plants with virulent or avirulent pathogens, nonpathogens, or biotic or abiotic defense activators can result in a localized or systemic resistance response $(6,11)$. Several products have been used as inducers of resistance (also referred to as elicitors or defense activators) in plants against pathogens, including chitosan $(4,20,28)$, salicylic acid analogues $(3,5,10,23)$, living or processed fungal products (15), and seaweed extracts (31).

The evidence concerning induced resistance to diseases in strawberry is very limited and, to our knowledge, nothing has been published on this phenomenon regarding crown rot or red stele. Chitosan (partly deacetylated chitin) has been used to induce resistance in many plant species against various pathogens. Some of the effects of chitosan treatment are lignification (1), increased phenylalanine ammonia lyase (PAL) and peroxidase activity (29), and accumulation of lipoxygenase (4). Chitosan has been shown to control postharvest infection of Botrytis cinerea and Rhizopus sp. in strawberry fruit $(21,22)$ and increase shelf life of sliced strawberry fruit (32); however, this material has not been tested as an inducer of disease resistance in strawberry plants. Acibenzolar- $S$ methyl (1,2,3-benzothiadiazole-7-thiocarboxylic acid S-methyl ester) is a well-studied defense activator that can activate resistance in many crops against fungi, bacteria, and viruses (17). Acibenzolar- $S$ methyl may enhance expression of glucanases and peroxidases (25) and lipoxygenases (10), increase levels of phenolic compounds, and increase PAL activity (25), and it is thought to be translocated systemically in plants (17).

The objective of this study was to determine if acibenzolar- $S$-methyl and chitosan induce resistance against crown rot and red stele in strawberry.

\section{MATERIALS AND METHODS}

Isolates of $P$. cactorum and $P$. fragariae var. fragariae. In all experiments involving inoculation with $P$. cactorum, a mixture of zoospores from two isolates (7574 and 9047), obtained from the rhizomes of fieldgrown strawberry plants in Norway were used. In the in vitro test, only isolate 9047 was used. In all experiments with $P$. fragariae var. fragariae, isolate 7661 , originating from field-grown strawberry plants in Norway, was used.

Zoospores of $P$. cactorum were produced by adding autoclaved, nutrient-rich pond water to petri dishes (approximately $20 \mathrm{ml}$ in each) containing pieces of V8 juice agar (330 $\mathrm{ml}$ of $\mathrm{V} 8$ juice, $1,320 \mathrm{ml}$ of distilled water, $3.3 \mathrm{~g}$ of $\mathrm{CaCO}_{3}$, and $25 \mathrm{~g}$ of agar) with mycelium of $P$. cactorum. The petri dishes were kept on the laboratory bench under fluorescent light for 2 days, followed by cooling in a refrigerator $\left(4\right.$ to $\left.5^{\circ} \mathrm{C}\right)$ for $30 \mathrm{~min}(9,12)$. The plates then were placed on the laboratory bench, and the concentration of zoospores usually reached $10^{6}$ zoospores per milliliter of water within $1 \mathrm{~h}$. The zoospore suspension always was prepared within $1 \mathrm{~h}$ before inoculation.

Cultures of $P$. fragariae var. fragariae were grown and stored at $15^{\circ} \mathrm{C}$ on V8 juice agar. To produce mycelium for inoculation, cultures were grown for 3 weeks.

Plant material, elicitors, inoculation, and disease assessment. Cold-stored strawberry plants were used in all experi- 
ments. The plants had been stored at approximately $-1.5^{\circ} \mathrm{C}$ for 2 months when delivered from the grower. All dead aboveground plant material was removed before the plants were planted in nonsterile sphagnum peat moss containing fertilizer and lime with a pH of 5.5 to 6 (Plantejord, Emmaljunga Torvmull AB, Sweden) in 8cm-diameter disposable pots. Before and during experiments, plants were kept in a greenhouse at $20^{\circ} \mathrm{C}$, with a $16-\mathrm{h}$ photoperiod. Supplemental light was provided by high-pressure sodium lamps (SON/T, approximately $130 \mu \mathrm{E} \mathrm{m}^{-2} \mathrm{~s}^{-1}$ ).

Acibenzolar-S-methyl (Bion WG 50; Novartis Ltd., Basel, Switzerland) and a chitosan oligosaccharide (Chitosan; Fluka Chemie AG, Buchs, Switzerland) were tested as putative activators of resistance to $P$. cactorum in strawberry. Chitosan was dissolved in $0.1 \%$ acetic acid in distilled water and acibenzolar-S-methyl in distilled water. Both elicitors were applied with $0.01 \%$ Triton X-100 (Union Carbide Chemicals and Plastics Co. Inc., St. Louis) as a dispersant. In addition to a nontreated control (water), $0.01 \%$ Triton X-100 and $0.01 \%$ acetic acid, alone and in combination, were used as controls. The final dilutions of all elicitors were always made within $2 \mathrm{~h}$ of application, and the $\mathrm{pH}$ of all solutions was recorded. The elicitors were sprayed onto the crown and lower part of the plants with a hand-powered sprayer.

The plants were inoculated by carefully applying $2 \mathrm{ml}$ of a zoospore suspension of $P$. cactorum $\left(7 \times 10^{4} \mathrm{ml}^{-1}\right)$ containing a mixture of two isolates onto the crown of each plant with a pipette. To maintain high relative humidity, plants were enclosed in white polyethylene bags for 4 days following inoculation.

For the inoculated plants, disease was scored on a scale from 1 to 8 , according to Bell et al. (2). Plants that died during the first week after inoculation were given a score of 8. Plants that died during the second, third, or fourth week scored 7, 6, or 5, respectively. After 4 weeks, the crowns of the remaining plants were cut longitudinally and scored based on the degree of necrosis: $1=$ no symptoms, $2=$ a few brown speckles, $3=$ small patches of necrosis, and $4=$ more than $50 \%$ of the crown width necrotic. Noninoculated plants (controls) were examined for deviations from normal growth during the experiment, with a final assessment of the crown and comparison to the nontreated controls after 4 weeks.

Time and dosage response of $P$. cactorum to acibenzolar- $S$-methyl and chitosan. 'Zephyr' strawberry plants were cold stored and treated as previously described. Light and temperature conditions, inoculation, treatment with acibenzolar- $S$-methyl and chitosan, and disease assessment were as described above.

Four concentrations of acibenzolar- $S$ methyl and chitosan were tested; 10, 50,
250 , or $1,000 \mu \mathrm{g}$ a.i. $\mathrm{ml}^{-1}$ ( $1 \mathrm{ml}$ per plant). All solutions contained $0.01 \%$ Triton X100 as a dispersant, and all treatments were applied 15 days after planting and 2 days before inoculation. To investigate the effect of timing of the acibenzolar- $S$-methyl and chitosan treatments, plants also were treated $20,10,4$, or 2 days before inoculation. Plants were inoculated 3 weeks after planting because of the need to inoculate plants soon after removal from cold storage $(2,9,19)$. Both acibenzolar- $S$-methyl and chitosan were applied at a concentration of $100 \mu \mathrm{g}$ a.i. $\mathrm{ml}^{-1}(1 \mathrm{ml}$ per plant) and contained $0.01 \%$ Triton X-100 as a dispersant.

In these experiments, 20 plants were inoculated and 5 plants served as noninoculated controls for each treatment in each of two experimental trials. In addition to the nontreated control (water), $0.01 \%$ Triton $\mathrm{X}-100$ and $0.01 \%$ acetic acid, alone and in combination, were used as controls. The first trial was performed in a greenhouse and the second in a growth chamber. The inoculated plants were arranged in a randomized block design (four blocks with five plants per treatment in each), but the noninoculated plants were kept separately to avoid cross contamination.

Comparison of elicitors and fungicide treatments against $P$. cactorum. Coldstored cv. Polka strawberry plants were treated either 20 or 5 days before inoculation, with either acibenzolar- $S$-methyl or chitosan at $100 \mu \mathrm{g}$ a.i. $\mathrm{ml}^{-1}(1 \mathrm{ml}$ per plant), or $5 \mathrm{ml}$ of fosetyl-Al (Aliette 80 WG, 2,400 $\mu \mathrm{g}$ a.i. $\mathrm{ml}^{-1}$; Aventis CropScience SA, Lyon, France) per plant. Application of acibenzolar-S-methyl, chitosan, and fosetyl-Al, as well as inoculation and scoring of disease, were performed as previously described. Two experimental trials were performed, each with the inoculated plants arranged in a randomized block design (four blocks including five plants for each treatment). The noninoculated plants were kept separate from the inoculated plants to avoid cross contamination. They were not randomized but otherwise were treated as the inoculated plants.

Effect of elicitors against $P$. fragariae var. fragariae. Two-month-old seedlings of alpine strawberry (Fragaria vesca L. var. alpina) cv. Alexandria were used in this experiment. Cultivars of this species are used as bait plants when screening strawberry roots for red stele infections, and are known to be very susceptible to the disease (8). Acibenzolar-S-methyl and chitosan were applied at two concentrations $\left(50\right.$ or $250 \mu \mathrm{g}$ a.i. $\mathrm{ml}^{-1} ; 1 \mathrm{ml}$ per plant). Solutions were prepared as previously described, and all contained $0.01 \%$ Triton X-100 as a dispersant. The plants were nontreated; treated with acibenzolar$S$-methyl or chitosan $40,20,10$, or 5 days before inoculation; or treated with fosetylAl 5 days before inoculation while still in plug trays. The plants were potted in 10- cm-diameter pots (two seedlings in each) in a 1:4 mixture of sand and sphagnum peat moss. Each plant was inoculated with $51-\mathrm{cm}^{2}$ discs of V8 juice agar with mycelium of $P$. fragariae var. fragariae (grown for 3 weeks at $15^{\circ} \mathrm{C}$ ) at planting. The agar discs with mycelium were placed next to the plug of roots ( 2 to $3 \mathrm{~cm}$ below the soil surface) of each plant at planting.

For each treatment, 20 plants were inoculated and 4 plants were left as noninoculated controls. The treatments were arranged in a completely randomized block design, with four plants (two pots) in each block. Disease was recorded as the number of dead plants after 4 and 6 weeks. In addition, fresh weight of all aboveground plant material was measured 6 and 8 weeks after inoculation (10 plants from each treatment each time). Before and during experiments, plants were kept in a growth chamber at $15^{\circ} \mathrm{C}$ and a $16-\mathrm{h}$ photoperiod. Artificial light was provided by high-pressure sodium lamps (SON/T, approximately 200

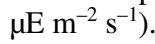

Effect of elicitors on $P$. cactorum and $P$. fragariae var. fragariae in vitro. To investigate their possible fungicidal effects, we tested the growth of one isolate each of $P$. cactorum and $P$. fragariae var. fragariae in vitro on media containing acibenzolar- $S$ methyl or chitosan. Both compounds were used in the concentrations $0.5,5,50$, and $500 \mu \mathrm{g}$ a.i. $\mathrm{ml}^{-1}$ in V8 juice agar. Stock solutions of 10 or $5 \mathrm{mg}$ a.i. $\mathrm{ml}^{-1}$ (acibenzolar- $S$-methyl or chitosan, respectively) were prepared as described above. Media were prepared in 100-ml flasks containing $95 \mathrm{ml}$ of media, and stock solutions of either acibenzolar-S-methyl or chitosan were added to obtain the desired concentrations. Distilled water was added to each flask to bring the total volume to $100 \mathrm{ml}$. Five milliliters of distilled water was added to the control flasks. Chitosan was added to the media before being autoclaved, whereas acibenzolar- $S$-methyl was added aseptically after the media had been autoclaved.

In each of two trials, five petri dishes, each containing $20 \mathrm{ml}$ of V8 juice agar, were made for each concentration of acibenzolar- $S$-methyl and chitosan. An agar disc (5 $\mathrm{mm}$ in diameter) with mycelium of $P$. cactorum or $P$. fragariae var. fragariae was placed in the center of each petri dish. Petri dishes were randomized and incubated at $20^{\circ} \mathrm{C}$ ( $P$. cactorum) or $15^{\circ} \mathrm{C}(P$. fragariae var. fragariae). Radial mycelial growth (in millimeters) was measured daily until it reached the margin of the plates.

Statistical analysis. Data were analyzed by analysis of variance, and significant treatment differences were separated by Fisher's protected least significant difference. In the time and dosage response studies, the data also were analyzed by linear regression, based on the treatment mean from each of the two trials. In the dosage 
response study, the disease score was regressed on the $\log _{10}$-transformed concentration. The experimental trials were included as a factor in the analysis.

\section{RESULTS}

All treatments with acibenzolar- $S$ methyl or chitosan against $P$. cactorum in the time-response study lowered the disease score significantly $(P<0.001)$ compared with the inoculated control (disease score 3.5). There were no significant differences between the two experimental trials. Analysis of variance showed no significant differences between times of application for acibenzolar-S-methyl, even when the nontreated control was omitted from the statistical analysis. For chitosan, the treatment 2 days before inoculation resulted in a higher $(P=0.02)$ disease score than treatment 20 days before inoculation. Analysis of the data by linear regression (Fig. 1) showed a slight, but significant decrease $(P=0.05$ for acibenzolar- $S$-methyl and $P=0.047$ for chitosan) in disease score for both compounds as time between treatment and inoculation increased.

There were no significant differences between the concentrations of acibenzolar$S$-methyl (with or without the nontreated control included in the analysis); however, all treatments resulted in a significantly lower $(P<0.001)$ disease score compared with the inoculated control (disease score 3.43). There were no significant differences between the two experimental trials. For chitosan at 10 and $50 \mu \mathrm{g}$ a.i. per plant, the disease scores were significantly lower $(P<0.001)$ than for 250 and $1,000 \mu \mathrm{g}$, and the three lowest concentrations of chitosan reduced the disease score significantly $(P<$ $0.001)$ compared with the control. Regression analysis of the data (Fig. 2) showed a significant linear increase $(P=$ $0.05)$ in disease score as the concentration of chitosan was increased. The decrease in disease score for acibenzolar- $S$-methyl was not significant.

Acibenzolar- $S$-methyl, chitosan, and fosetyl-Al (Fig. 3) all provided similar disease control against $P$. cactorum, and all treatments reduced the disease score significantly $(P<0.001)$ compared with the control. There were no significant differences between the two experimental trials. Chitosan applied 5 days before inoculation resulted in a significantly higher disease score $(P=0.04)$ than the other treatments.

Fresh weights of 'Alexandria' seedlings treated with chitosan 6 or 8 weeks after inoculation with $P$. fragariae var. fragariae (Table 1) did not differ significantly from those of the nontreated, inoculated control. Both acibenzolar- $S$-methyl (all treatments) and fosetyl-Al increased the average fresh weight compared with the inoculated control $(P<0.001)$. The only treatments that did not significantly reduce seedling fresh weight relative to the noninoculated con- trols were fosetyl-Al and acibenzolar- $S$ methyl at $250 \mu \mathrm{g}$ a.i. applied 5 days before inoculation when measured 8 weeks after inoculation. Fresh weight of seedlings treated with acibenzolar- $S$-methyl at 250 $\mu \mathrm{g}$ a.i. 5 or 40 days before inoculation did not differ significantly from that of seedlings treated with fosetyl-Al when fresh weight was measured either 6 or 8 weeks after inoculation.

None of the noninoculated plants showed physical signs of injury from the elicitors in the experiments with $P$. cactorum. In the experiment with $P$. fragariae var. fragariae, the fresh weight of noninoculated plants treated with acibenzolar$S$-methyl, chitosan, or fosetyl-Al did not differ significantly from the control (data not shown).

Testing of elicitors in vitro showed that acibenzolar- $S$-methyl did not reduce the growth rate of $P$. cactorum at any concentration, whereas chitosan reduced the growth rate at 50 and $500 \mu \mathrm{g}$ a.i. $\mathrm{ml}^{-1}(P=$ 0.001 ; Table 2). Both acibenzolar- $S$-methyl and chitosan reduced the growth rate of $P$. fragariae var. fragariae at the highest concentration $\left(500 \mu \mathrm{g}\right.$ a.i. $\left.\mathrm{ml}^{-1} ; P=0.05\right)$. There were no significant differences between the two experimental trials.

\section{DISCUSSION}

These experiments demonstrated that the use of defense activators can enhance resis-

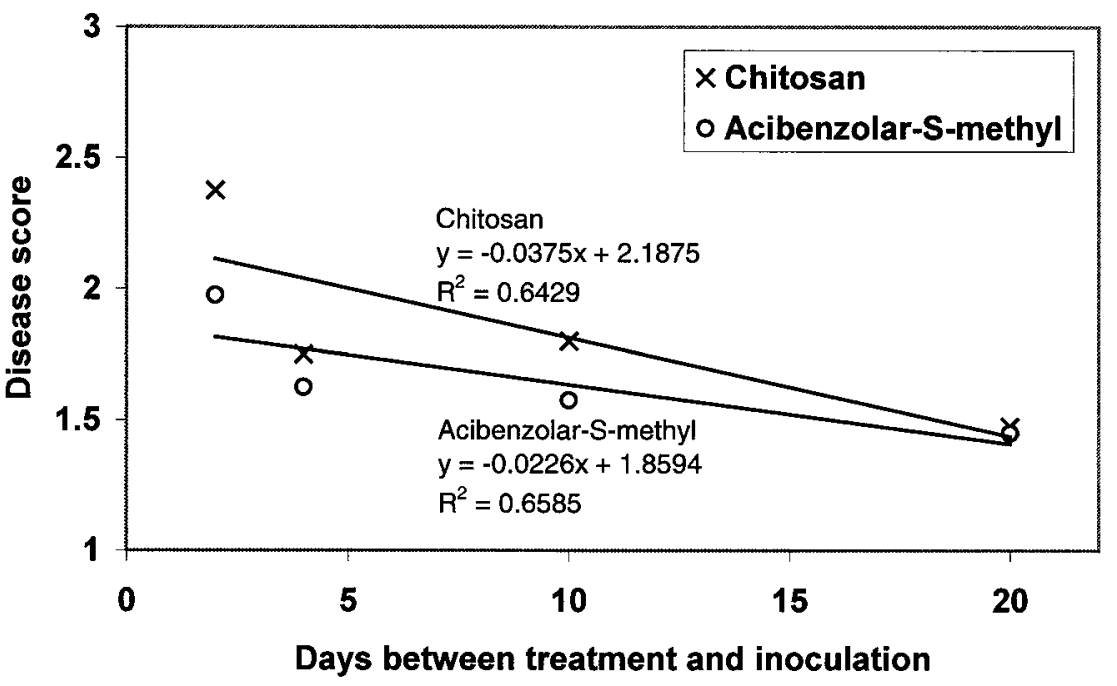

Fig. 1. Disease score for strawberry plants (cv. Zephyr) treated with acibenzolar-S-methyl or chitosan (100 $\mu$ g a.i. $\mathrm{ml}^{-1} ; 1 \mathrm{ml}$ per plant) 2, 4, 10, or 20 days before inoculation with Phytophthora cactorum. Disease was scored on a scale from 1 to 4 based on degree of necrosis in the rhizome of the surviving plants 4 weeks after inoculation, and 5 to 8 during 4 weeks based on when the plants died. Data points are means from two trials (four blocks with five plants per treatment in each trial).

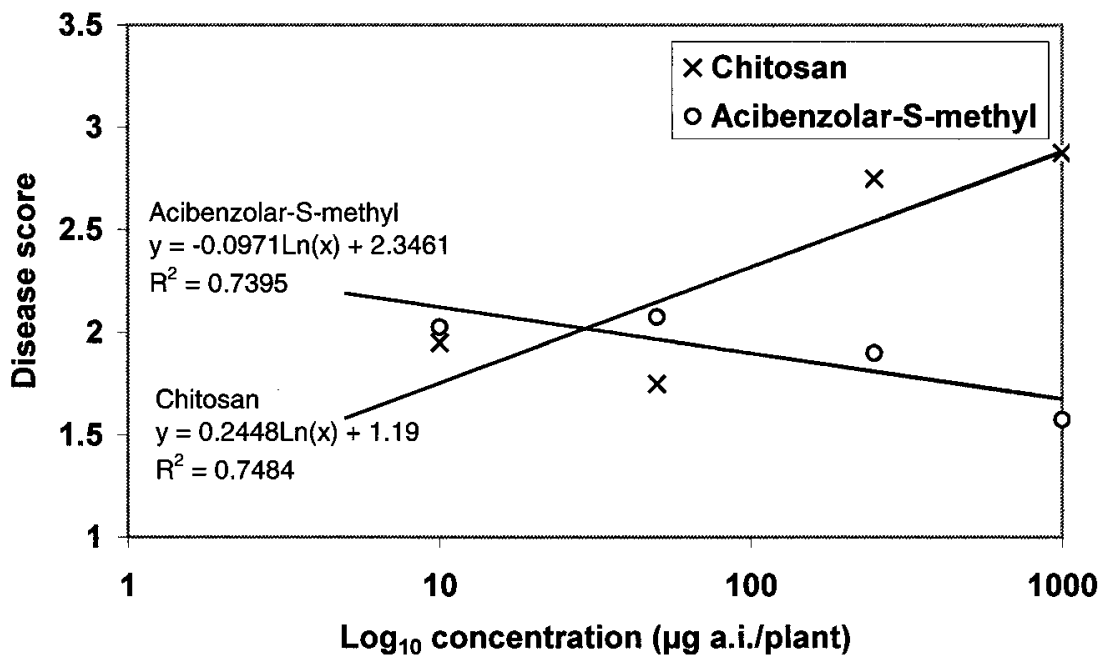

Fig. 2. Disease score for strawberry plants (cv. Zephyr) treated with five concentrations of acibenzolar-S-methyl or chitosan 2 days before inoculation with Phytophthora cactorum. Disease was scored on a scale from 1 to 4 based on degree of necrosis in the rhizome of the surviving plants 4 weeks after inoculation, and 5 to 8 during 4 weeks based on when the plants died. Data points are means from two trials (four blocks with five plants per treatment in each trial). 
tance to crown rot and red stele in strawberry. Both acibenzolar- $S$-methyl and chitosan reduced crown rot symptoms, and the effect was enhanced when the time between treatment and inoculation was increased from 2 to 20 days. This increase in effect over time also has been shown in other plant pathosystems. For powdery mildew on wheat, treatments with acibenzolar-S-methyl 4 or 7 days before inocula- tion decreased the amount of infected leaf area more than if applied 1 day before inoculation (10). In apple, treatment with acibenzolar-S-methyl increased resistance to fire blight and decreased the percentage of infected leaves when the time between application and inoculation was increased from 2 to 10 days (5). Cold-stored strawberry plants are most susceptible to crown rot during the first 2 to 3 weeks after cold

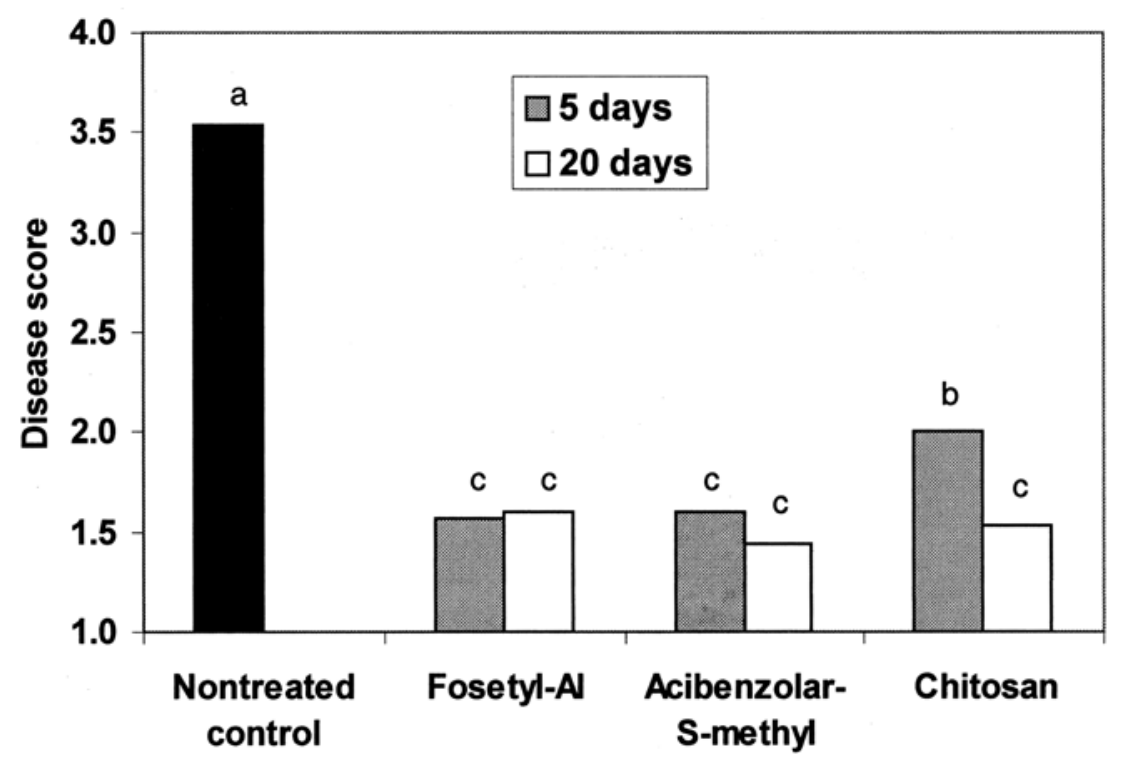

Fig. 3. Disease score for strawberry plants (cv. Polka) treated with fosetyl-Al $\left(2,400 \mu \mathrm{g}\right.$ a.i. $\mathrm{ml}^{-1}, 5$ $\mathrm{ml}$ per plant), or acibenzolar- $S$-methyl or chitosan (100 $\mu \mathrm{g}$ a.i. per plant), 5 or 20 days before inoculation with Phytophthora cactorum, compared with a nontreated, inoculated control. Disease was scored on a scale from 1 to 4 based on degree of necrosis in the rhizome of the surviving plants 4 weeks after inoculation, and 5 to 8 during 4 weeks based on when the plants died. Numbers are means of four blocks (five plants in each) in each of two trials, and different letters indicate significant difference $(P \leq 0.05)$ according to Fisher's protected least significant difference. storage (19). Therefore, the possible effect of a further delay between treatment and inoculation was difficult to investigate.

Testing several dosages of acibenzolar$S$-methyl and chitosan showed that high concentrations of chitosan were less effective against crown rot than low concentrations, whereas the effect of acibenzolar- $S$ methyl against crown rot increased up to $1,000 \mu \mathrm{g}$ a.i. per plant when plants were treated 2 days before inoculation. In wheat, the effect of different concentrations of chitosan (measured as lipoxygenase activity) increased up to $100 \mu \mathrm{g}$ a.i. $/ \mathrm{ml}$, whereas $1,000 \mu \mathrm{g}$ a.i./ml resulted in lower activity (4). These results are consistent with findings obtained with different concentrations and times of application in these experiments, and help to explain the decreasing effect of chitosan against crown rot when applied at high concentrations. The experiment that included fosetyl-Al demonstrated that there were no or only slight differences among the effects of fosetyl-Al, acibenzolar- $S$-methyl, and chitosan.

Inoculation of strawberry plants with $P$. fragariae var. fragariae after treatments with acibenzolar- $S$-methyl, chitosan, or fosetyl-Al showed that acibenzolar- $S$ methyl provided good disease control, whereas chitosan had no effect at all. The evidently long-lasting effect of acibenzolar-S-methyl against $P$. fragariae var. fragariae shown in these experiments is consistent with experiments in wheat, where acibenzolar-S-methyl conferred resistance against powdery mildew up to 10 weeks after treatment (23). The experiment with acibenzolar-S-methyl and chitosan in vitro demonstrated that there was no

Table 1. Fresh weight and death of strawberry plants (Fragaria vesca var. alpina, cv. Alexandria) after inoculation with Phytophthora fragariae var. fragariae at different times after treatment with two putative defense elicitors or fosetyl-Al

\begin{tabular}{|c|c|c|c|c|c|}
\hline \multirow[b]{2}{*}{ Treatment $^{y}$} & \multirow[b]{2}{*}{ Application (days) $^{\mathrm{z}}$} & \multicolumn{2}{|c|}{ Fresh weight $(\mathbf{g})^{\mathrm{w}}$} & \multicolumn{2}{|c|}{ No. of dead plants ${ }^{x}$} \\
\hline & & 8 weeks & 6 weeks & 4 weeks & 6 weeks \\
\hline \multirow[t]{4}{*}{ Acibenzolar-S-methyl, $50 \mu \mathrm{g}$ a.i./plant } & 5 & $2.99 \mathrm{e}$ & $3.46 \mathrm{c}$ & 0 & 1 \\
\hline & 10 & $6.35 \mathrm{c}$ & $5.04 \mathrm{~b}$ & 0 & 0 \\
\hline & 20 & $4.00 \mathrm{~d}$ & $3.49 \mathrm{c}$ & 0 & 2 \\
\hline & 40 & $4.32 \mathrm{~d}$ & $2.81 \mathrm{c}$ & 0 & 5 \\
\hline \multirow[t]{4}{*}{ Acibenzolar-S-methyl, $250 \mu \mathrm{g}$ a.i./plant } & 5 & $8.37 \mathrm{a}$ & $4.68 \mathrm{~b}$ & 0 & 0 \\
\hline & 10 & $5.86 \mathrm{c}$ & $3.42 \mathrm{c}$ & 0 & 0 \\
\hline & 20 & $6.18 \mathrm{c}$ & $3.72 \mathrm{c}$ & 0 & 0 \\
\hline & 40 & $6.56 \mathrm{~b}$ & $5.38 \mathrm{~b}$ & 0 & 0 \\
\hline \multirow[t]{4}{*}{ Chitosan, $50 \mu \mathrm{g}$ a.i./plant } & 5 & $1.11 \mathrm{f}$ & $1.02 \mathrm{~d}$ & 15 & 20 \\
\hline & 10 & $0.68 \mathrm{f}$ & $1.03 \mathrm{~d}$ & 19 & 20 \\
\hline & 20 & $0.74 \mathrm{f}$ & $0.85 \mathrm{~d}$ & 17 & 20 \\
\hline & 40 & $1.44 \mathrm{f}$ & $1.44 \mathrm{~d}$ & 8 & 20 \\
\hline \multirow[t]{4}{*}{ Chitosan, $250 \mu \mathrm{g}$ a.i./plant } & 5 & $0.90 \mathrm{f}$ & $1.18 \mathrm{~d}$ & 14 & 20 \\
\hline & 10 & $1.00 \mathrm{f}$ & $0.96 \mathrm{~d}$ & 18 & 20 \\
\hline & 20 & $0.88 \mathrm{f}$ & $0.74 \mathrm{~d}$ & 15 & 20 \\
\hline & 40 & $0.89 \mathrm{f}$ & $1.08 \mathrm{~d}$ & 18 & 20 \\
\hline Fosetyl-Al, $12 \mathrm{mg}$ a.i./plant & 5 & $7.60 \mathrm{ab}$ & $5.38 \mathrm{~b}$ & 0 & 0 \\
\hline \multicolumn{6}{|l|}{ Control (water) } \\
\hline Inoculated & $\ldots$ & $0.78 \mathrm{f}$ & $0.89 \mathrm{~d}$ & 18 & 20 \\
\hline Noninoculated & $\ldots$ & $8.64 \mathrm{a}$ & $6.81 \mathrm{a}$ & 0 & 0 \\
\hline
\end{tabular}

${ }^{\text {w}}$ Mean fresh weight of 10 plants 6 or 8 weeks after inoculation, including all aboveground plant material. Means followed by the same letter are not significantly different $(P \leq 0.05)$ according to Fisher's protected least significant difference.

${ }^{x}$ Number of dead plants 4 and 6 weeks after inoculation. $N=20$.

y Chemical applied and concentration.

${ }^{\mathrm{z}}$ Number of days between treatment and inoculation. 
or only a very slight (at the highest concentrations) growth-retarding effect on the mycelium. Chitosan reduced the growth rate of $P$. cactorum and $P$. fragariae var. fragariae at the highest concentrations tested, but this may have been due to the fact that chitosan did not dissolve properly at these concentrations. Especially when added at $500 \mu \mathrm{g}$ a.i. $\mathrm{ml}^{-1}$, the chitosan had a tendency to clump and was not uniformly distributed in the petri dishes. The highest concentrations of both acibenzolar- $S$ methyl and chitosan significantly reduced the growth rate of $P$. fragariae var. fragariae, but this slight growth retardation cannot explain the reduction in disease severity experienced in the greenhouse.

None of the treatments in any of these experiments conferred complete protection against $P$. cactorum or $P$. fragariae var. fragariae. Even plants treated with fosetyl$\mathrm{Al}$ showed symptoms, which suggests that complete protection was not possible in these experiments due to optimal climatic conditions for infection and high inoculum concentration. An important concern is whether the results in the field will be comparable to those from greenhouse experiments. There are many reports demonstrating the effect of induced resistance against pathogens in the greenhouse, but few have been tested under field conditions (16). The increased physiological expense of induced resistance for the plant and the possible impact on yield, winter survival, and other factors is also of concern $(13,14)$. Fresh weight was recorded in the alpine strawberry in these experiments, and there were no differences between untreated plants and plants treated with elicitors. However, no yield was recorded, and the experiment did not last long enough for any physiological effects to become evident. Environmental interactions, variation in pathogen epidemiology, and abiotic stress can be encountered in the field and may impact the effectiveness of these treatments (16). Before compounds like

Table 2. Growth of Phytophthora cactorum (at $20^{\circ} \mathrm{C}$ ) and P. fragariae var. fragariae (at $15^{\circ} \mathrm{C}$ ) on $\mathrm{V} 8$ juice agar containing four different concentrations of acibenzolar- $S$-methyl or chitosan and a nontreated control

\begin{tabular}{|c|c|c|}
\hline \multirow[b]{2}{*}{ Treatment, concentration $(\mu \mathrm{g}$ a.i./ml) } & \multicolumn{2}{|c|}{ Rate of growth $\left(\mathrm{mm} \mathrm{day}^{-1}\right)^{\mathrm{z}}$} \\
\hline & P. cactorum & P. fragariae var. fragariae \\
\hline \multicolumn{3}{|l|}{ Acibenzolar-S-methyl } \\
\hline 0.5 & 10.41 & 2.17 \\
\hline 5 & 10.79 & 2.07 \\
\hline 50 & 11.02 & 1.98 \\
\hline 500 & 10.03 & $1.72 *$ \\
\hline \multicolumn{3}{|l|}{ Chitosan } \\
\hline 0.5 & 10.37 & 2.26 \\
\hline 5 & 9.93 & 2.02 \\
\hline 50 & $9.22 *$ & 1.94 \\
\hline 500 & $7.26^{*}$ & $1.78 *$ \\
\hline \multicolumn{3}{|l|}{ Control } \\
\hline 0 & 10.29 & 2.04 \\
\hline
\end{tabular}

${ }^{\mathrm{z}}$ Numbers are means of colony diameters from five petri dishes in each of two trials. Means followed by an asterisk are significantly lower $(P \leq 0.05)$ than the control according to Fisher's protected least significant difference. field, a better understanding of interactions with other factors is needed, so that application, timing, and possible integration with pesticides or other cultural measures can be optimized. The very promising effect of acibenzolar-S-methyl against crown rot and red stele and chitosan against crown rot indicates that these compounds may be future alternatives to traditional chemicals for disease control.

Barber, M. S., Bertram, R. E., and Ride, J. P. 1989. Chitin oligosaccharides elicit lignificaPlant P. 34:3-12.

2. Bell, J. A., Simpson, D. W., and Harris, D. C. 1997. Development of a method for screening strawberry germplasm for resistance to Phytophthora cactorum. Acta Hortic. 439:175179.

3. Benhamou, N., and Belanger, R. R. 1998. Benzothiadiazole-mediated induced resistance to Fusarium oxysporum f. sp. radicis-lycopersici in tomato. Plant Physiol. 118:1203-1212. ner, I., and Grambow, H. J. 1997. Differential induction of lipoxygenase isoforms in wheat upon treatment with rust fungus elicitor, chiin oligosaccharides, chitosan, and methyl jasmonate. Plant Physiol. 114:679-685.

5. Brisset, M. N., Cesbron, S., Thomson, S. V., and Paulin, J. P. 2000. Acibenzolar-S-methyl induces the accumulation of defense-related enzymes in apple and protects from fire blight. Eur. J. Plant Pathol. 106:529-536.

6. den Hond, F. 1998. Systemic acquired resisance: a case of innovation in crop protection. Pestic. Outl. 9:18-23.

7. Deutschmann, V. F. 1954. Eine Wurzelfäule an Erdbeeren, Hervorgerufen durch Phytophthora cactorum (Leb et Cohn) Schroet. Nachrichtenbl. Dtsch. Pflanzenschutzdienstes. 6:7-9.

8. Duncan, J. M. 1980. A technique for detecting red stele (Phytophthora fragariae) infection of strawberry stocks before planting. Plant Dis. 64:1023-1025.

9. Eikemo, H., Stensvand, A., and Tronsmo, A. M. 2000. Evaluation of methods of screening strawberry cultivars for resistance to crown rot caused by Phytophthora cactorum. Ann. Appl. Biol. 137:237-244.

10. Görlach, J., Volrath, S., Knauf-Beiter, G., acibenzolar- $S$-methyl can be applied in the

\section{LITERATURE CITED}

4. Bohland, C., Balkenhohl, T., Loers, G., Feuss-
Hengy, G., Beckhove, U., Kogel, K. H., Oostendorp, M., Staub, T., Ward, E., Kessmann, H., and Ryals, J. 1996. Benzothiadiazole, a novel class of inducers of systemic acquired resistance, activates gene expression and disease resistance in wheat. Plant Cell 8:629-643.

11. Hammerschmidt, R. 1999. Induced disease resistance: How do induced plants stop pathogens? Physiol. Mol. Plant P. 55:77-84.

12. Harris, D. C. 1986. Methods for preparing, estimating and diluting suspensions of Phytophthora cactorum zoospores. Trans. Br. Mycol. Soc. 86:482-486.

13. Heil, M. 2001. The ecological concept of costs of induced systemic resistance (ISR). Eur. J. Plant Pathol. 107:137-146.

14. Heil, M., Hilpert, A., Kaiser, W., and Linsenmair, K. E. 2000. Reduced growth and seed set following chemical induction of pathogen defence: does systemic acquired resistance (SAR) incur allocation costs? J. Ecol. 88:645654.

15. Hjeljord, L. G., Stensvand, A., and Tronsmo, A. 2000. Effect of temperature and nutrient stress on the capacity of commercial Trichoderma products to control Botrytis cinerea and Mucor piriformis in greenhouse strawberries. Biol. Control 19:149-160.

16. Lyon, G. D., and Newton, A. C. 1997. Do resistance elicitors offer new opportunities in integrated disease control strategies? Plant Pathol. 46:636-641.

17. Oostendorp, M., Kunz, W., Dietrich, B., and Staub, T. 2001. Induced disease resistance in plants by chemicals. Eur. J. Plant Pathol 107:19-28.

18. Parikka, P. 1991. Phytophthora cactorum on strawberry in Finland. Nord. Jordbrugsforsk. 73:121.

19. Pettitt, T. R., and Pegg, G. F. 1994. Sources of crown rot (Phytophthora cactorum) infection in strawberry and the effect of cold storage on susceptibility to the disease. Ann. Appl. Biol. 125:279-292.

20. Reddy, M. V. B., Arul, J., Angers, P., and Couture, L. 1999. Chitosan treatment of wheat seeds induces resistance to Fusarium graminearum and improves seed quality. J. Agric. Food Chem. 47:1208-1216.

21. Reddy, M. V. B., Belkacemi, K., Corcuff, R., Castaigne, F., and Arul, J. 2000. Effect of preharvest chitosan sprays on post-harvest infection by Botrytis cinerea and quality of strawberry fruit. Postharvest Biol. Biotechnol. 20:39-51.

22. Romanazzi, G., Nigro, F., and Ippolito, A. 2000. Effectiveness of pre and postharvest chitosan treatments on storage decay of strawberries. Riv. Fruttic. Vitic. Ortic. 62:71-75.

23. Ruess, W., Mueller, K., Knauf-Beiter, G., and Kunz, W. 1997. Plant activator Bion 50 WG: an innovative approach for disease control in cereals. Prog. Plant Prot. 37:36-41.

24. Simpson, D. W., Bell, J. A., and Harris, D. C. 1994. Breeding for resistance to fungal diseases in strawberry. Pages 63-66 in: Progress in Temperate Fruit Breeding. H. Schmidt and M. Kellerhals, eds. Kluwer Academic Publishers, Dordrecht, Netherlands.

25. Stadnik, M. J., and Buchenauer, H. 2000. Inhibition of phenylalanine ammonia-lyase suppresses the resistance induced by benzothiadiazole in wheat to Blumeria graminis f. sp. tritici. Physiol. Mol. Plant Pathol. 57:25-34.

26. Stensvand, A., and Herrero, M. L. 1997. Presence of Phytophthora fragariae var. fragariae in Norway. EPPO Bull. 27:243-248.

27. Stensvand, A., Herrero, M. L., and Talgø, V. 1999. Crown rot caused by Phytophthora cactorum in Norwegian strawberry production. EPPO Bull. 29:155-158.

28. Tiuterev, S., Yakubchik, M., Tarlakovsky, S., 
Popova, E., Vytsky, V., and Dorofeyeva, T. 1996. Chitosan: mechanism of action and ways of using as ecologically safe means in enhancement of plant disease resistance. Arch. Phytopathol. Plant Prot. 30:323-332.

29. Vander, P., Varum, K. M., Domard, A., El Gueddari, N. E., and Moerschbacher, B. M.
1998. Comparison of the ability of partially $\mathrm{N}$-acetylated chitosans and chitooligosaccharides to elicit resistance reactions in wheat leaves. Plant Physiol. 118:1353-1359.

30. Wardlaw, C. W. 1927. Lanarkshire strawberry disease. Scot. J. Agric. 11:65-71.

31. Washington, W. S., Engleitner, S., Boontjes,
G., and Shanmuganathan, N. 1999. Effect of fungicides, seaweed extracts, tea tree oil, and fungal agents on fruit rot and yield in strawberry. Aust. J. Exp. Agric. 39:487-494.

32. Yoo, S. Y., and Lee, S. K. 1999. Effect of various films on shelf life of sliced strawberry fruit. Acta Hortic. 483:283-289. 